\title{
How does the built environment affect transit use by train, tram and bus?
}

\author{
Chris De Gruyter \\ RMIT University \\ chris.degruyter@rmit.edu.au \\ Liang Ma \\ Peking University \\ liang.ma@pku.edu.cn
}

\author{
Tayebeh Saghapour \\ RMIT University \\ tayebeh.saghapour@rmit.edu.au \\ Jago Dodson \\ RMIT University \\ jago.dodson@rmit.edu.au
}

\begin{abstract}
While much research has explored the influence of the built environment on public transport use, little focus has been given to how this influence varies by public transport mode. Using a case study of Melbourne, this study assesses the influence of the built environment and other characteristics (transit service quality, demand management and socio-demographics) on commuting by train, tram and bus. Key findings indicate that the built environment has a significant influence, but with notable differences between individual public transport modes. Commuting by tram was found to have the strongest association with the explanatory variables, while bus had the weakest explanatory power. Differences in the geographical coverage of public transport services in Melbourne play a key role in explaining the influence of the built environment. Population density is positively associated with tram use, which operates in older, higher density environments, but is negatively associated with train and bus use. Furthermore, the association with land-use mix is only significant for train and tram use, as buses tend to operate in areas with greater land-use homogeneity. When focused on inner Melbourne only, the influence of the built environment is diluted, while distance to public transport becomes more significant. The findings have important implications for practice, not only in terms of improving transit demand forecasting but also in targeting changes to the built environment to leverage higher transit ridership by mode.
\end{abstract}

Keywords: Transit, public transport, commuting, built environment, travel behavior, Melbourne

\section{Article history:}

Received: February 19, 2020

Received in revised form:

June 18, 2020

Accepted: July 22, 2020

Available online: November 20,

2020

Copyright 2020 Chris De Gruyter, Tayebeh Saghapour, Liang Ma \& Jago Dodson http://dx.doi.org/10.5198/jtlu.2020.1739

ISSN: 1938-7849 | Licensed under the Creative Commons Attribution - Noncommercial License 4.0

The Journal of Transport and Land Use is the official journal of the World Society for Transport and Land Use (WSTLUR) and is published and sponsored by the University of Minnesota Center for Transportation Studies. 


\section{Introduction}

Public transport serves an important role in both cities and regional areas across the world. Not only does this form of transport support efforts to reduce car dependency and traffic congestion (Cullinane, 2002; Goodwin, 1993; Nguyen-Phuoc, Currie, De Gruyter, \& Young, 2018), it can also enhance road safety (Truong \& Currie, 2019), reduce social exclusion (Currie, 2010), and contribute to sustainability (De Gruyter, Currie, \& Rose, 2016) and public health objectives (Badland, Rachele, Roberts, \& GilesCorti, 2017). Public transport can also influence urban geography via effects on built form and structure (Kasraian, Maat, Stead, \& Van Wee, 2016).

An understanding of the spatial factors that influence public transport use is critical for planning purposes and can inform approaches for increasing transit ridership and meeting wider societal objectives (Chow, Zhao, Liu, Li, \& Ubaka, 2006; Taylor, Miller, Iseki, \& Fink, 2009). Much research has explored the influence of factors relating to the built environment on public transport use, car ownership and travel behavior more generally (Cervero \& Kockelman, 1997; Ewing \& Cervero, 2010; NASEM, 2006; Tsai, Mulley, \& Clifton, 2012; Zegras, 2010; Zhang, Hong, Nasri, \& Shen, 2012). However, these studies tend to consider all public transport modes in aggregate form, with very limited consideration of how factors may vary by individual public transport mode, e.g., train, tram and bus. There are of course good reasons for this, such as (but not limited to) small sample sizes in datasets relating to individual public transport modes and a greater focus on understanding factors that influence car use vs. non-car use (Boulange et al., 2017; Cervero \& Murakami, 2010; McKibbin, 2011). Furthermore, and mainly due to data availability constraints, most studies of the built environment and travel behavior tend to neglect more specific transit-related variables known to strongly influence public transport use, such as transit service frequency (NASEM, 2006).

Given the transport geography literature has not systematically differentiated between modes in analysis of interactions with the built environment, there is a need for studies that respond to this oversight. The aim of the present study is to understand how the built environment and other characteristics affect transit use for commuting (to work) by mode, specifically train, tram and bus services. This paper asks 1) how do built environment and other characteristics affect transit use for commuting by mode for tram, train and bus services? 2) how can a multi-modal single city case study assist to detail these modal built environment differences? and 3) what implications might differences in modal relationships with the built environment pose for integrated transport and land-use planning decisions?

A case study of Melbourne was chosen for the research due to the presence of an extensive and integrated public transport system (train, tram and bus) and the availability of suitable data on the built environment and related characteristics for the analysis. Melbourne is located in the southeast corner of the Australian mainland and is home to over 5 million people (ABS, 2019). While the analysis is specific to Melbourne, the findings also have strong relevance for similar jurisdictions that operate multiple public transport modes within the same city.

This research contributes to the literature through providing an understanding of how factors affecting public transport commuting (to work) vary by train, tram and bus, within the same metropolitan region. Using a transit commuting dataset compiled for the year of 2016, the research draws upon a much larger sample size $(\mathrm{n}>10,000)$ than is typically available in studies of the built environment and travel behavior, and also incorporates other transit-related variables known to influence public transport use, such as service frequency. An understanding of factors affecting public transport use, individually by mode, can better inform transit planning and efforts to increase ridership by mode, while also providing an important input to transit demand forecasting.

This remainder of this paper is structured as follows. Section 2 provides an overview of the relevant literature, with a particular focus on studies that have assessed the influence of the built environment on travel behavior. Section 3 provides context for the research through a description of Melbourne as the 
chosen case study location, along with an overview of its public transport system. Section 4 details the analysis method employed to understand factors affecting transit use by mode, including the compilation of data and the modelling approach. Results of the analysis are then presented in Section 5, followed by a discussion of implications and concluding remarks in Section 6.

This research focuses mainly on the origin end of public transport commuting trips, represented by household locations in small geographical areas across Melbourne. Attributes specific to the destination end of commuting trips (e.g., car parking availability, price) are therefore not captured by the analysis. The research is also cross-sectional in nature, limiting the ability to attribute causation. The findings are therefore reported as "associations" between built environment characteristics and the use of public transport for commuting purposes.

\section{Literature review}

Table 1 provides a synthesis of key factors that can influence travel behavior, including public transport use. This synthesis is based on a total of 46 publications and is by no means exhaustive given the volume of research that has been undertaken on this topic. However, it does serve to provide a sufficient understanding of the range of factors that can influence public transport use.

The factors listed in Table 1 are categorised under the commonly cited 7 Ds (Ewing \& Cervero, 2010) of density, diversity, design, destination accessibility, distance to transit, demand management, and demographics. An additional category is also included to capture "other" factors reported by the literature. These categories contain some overlap, so are not mutually exclusive, but help to provide a useful classification of variables considered in previous studies. In addition, "distance to transit" contains a number of non-distance related variables (e.g., transit service frequency, route density) but are included under this category for convenience of grouping transit-related variables together.

To help contain the number of factors to a manageable level, Table 1 only includes factors that were reported by at least two studies. Examples of factors reported by only one study each included bicycle ownership (Lin \& Yu, 2011), pet ownership (Crane, 2000), political party affiliation (Taylor et al., 2009) and topography (Zegras, 2010). Table 1 also indicates whether or not each factor was statistically significant, although it is noted that statistical significance was not tested in some studies, such as literature reviews (Cervero, Ferrell, \& Murphy, 2002; Crane, 2000).

As shown in Table 1, the most common factors identified by the literature include:

1. Car/vehicle ownership (29 studies)

2. Income (27 studies)

3. Land-use mix (26 studies)

4. Population density (22 studies)

5. Distance to transit station/stop (21 studies)

6. Intersection/street density (21 studies)

7. Employment density (19 studies)

8. Jobs accessible within $\mathrm{x}$ mins by mode, transit service quality, adults/children/workers in house hold, and household size (17 studies each).

While land-use mix and employment density were commonly identified by the literature, a much smaller number of studies that tested for statistical significance ( 7 out of 20 studies for land-use mix; 7 out of 15 studies for employment density) reported these variables as significant. While transit service quality is acknowledged as a key factor affecting public transport use, it was included in only 17 studies, making it the 8 th most common factor identified by the literature (equal with a number of other factors). 


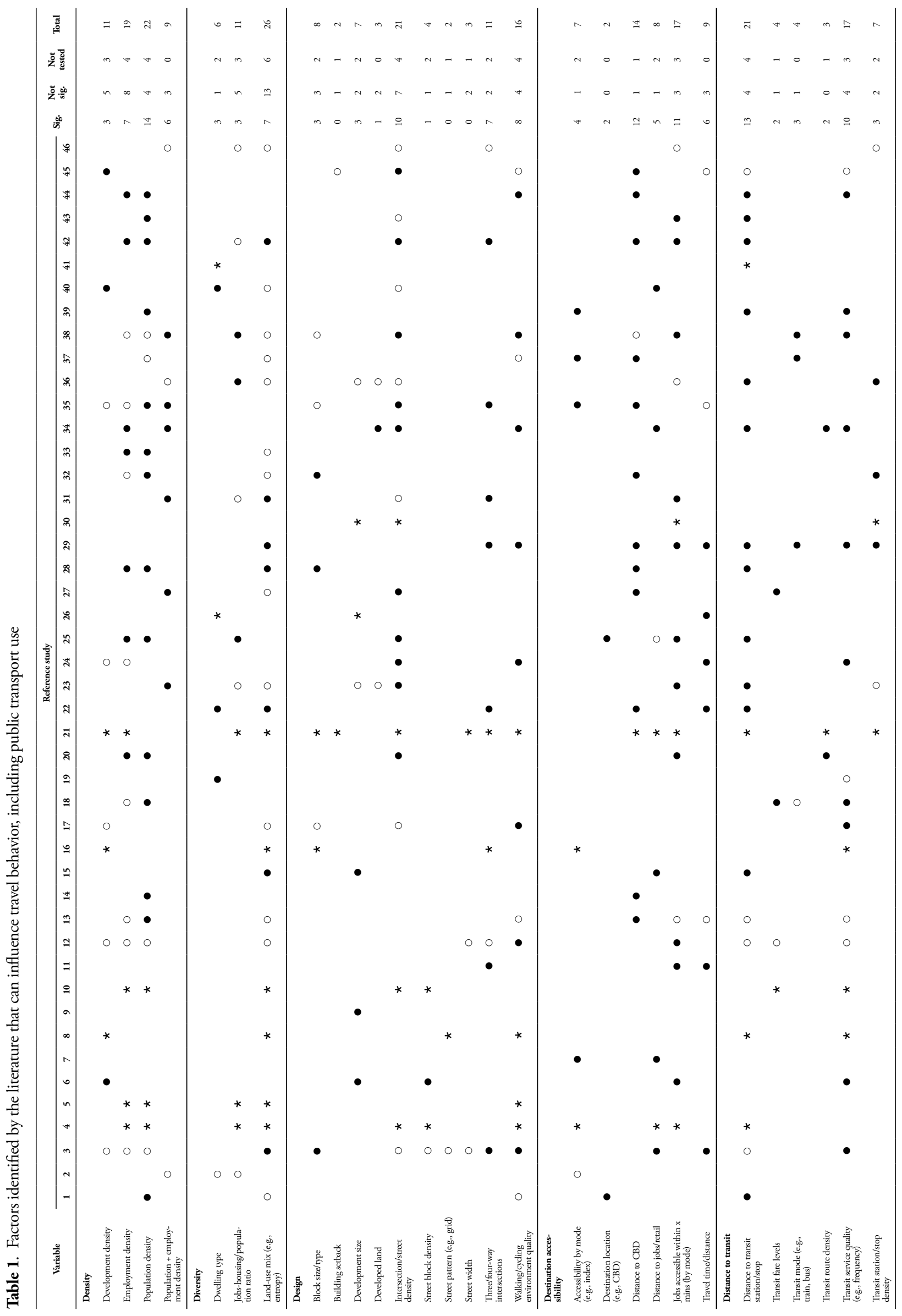




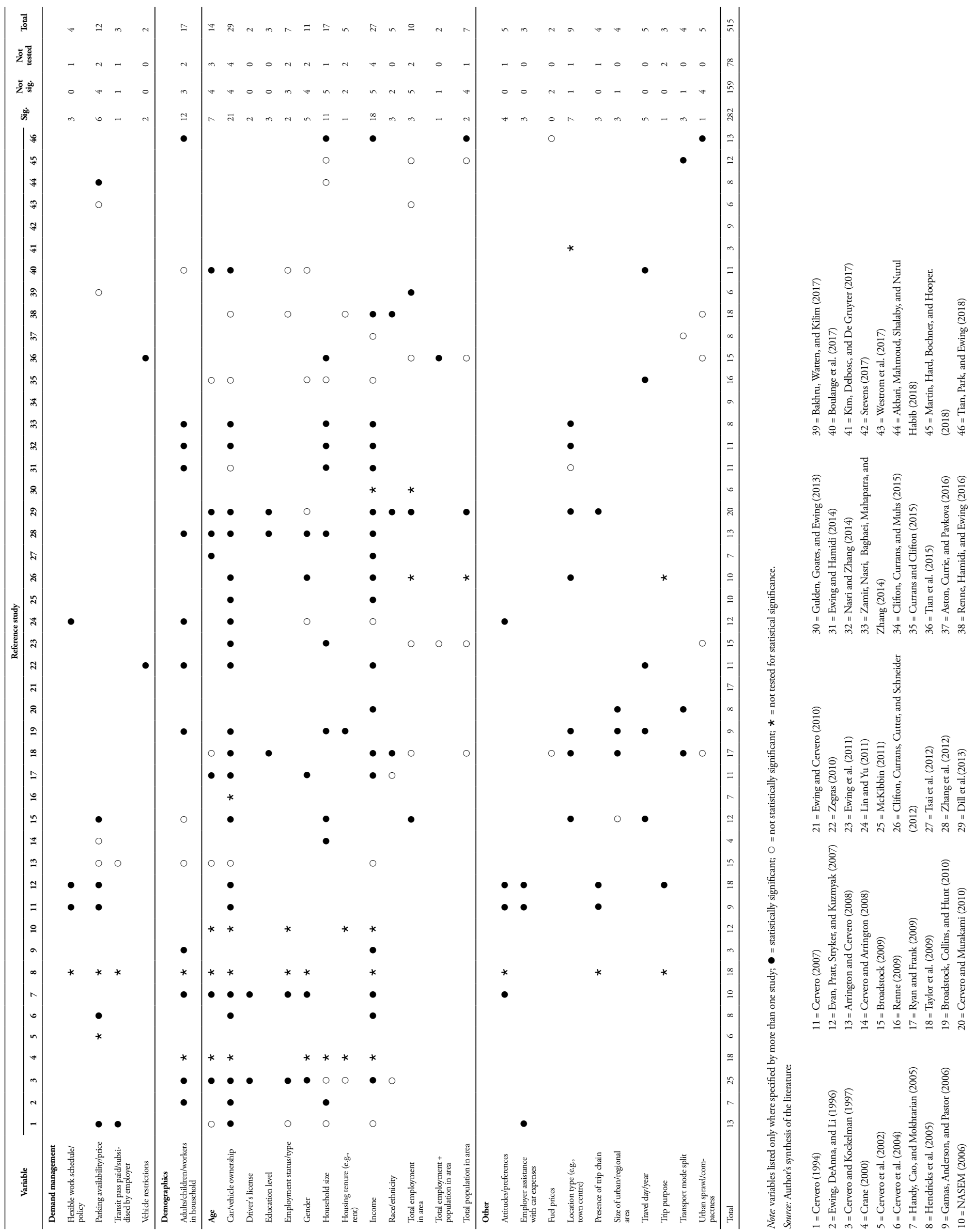


Table 1 also shows that a collective total of 515 variables were considered across the 46 studies, resulting in an average of approximately 11 explanatory variables per study. Of the 441 variables that were tested for statistical significance, 282 (or 64\%) were reported to be significant in influencing travel behavior. As noted by some researchers, urban design features (e.g., land-use mix, quality of walking environment) generally have a modest influence on public transport use compared with more direct factors such as distance to transit and the quality of public transport services (Arrington \& Cervero, 2008; Hendricks et al., 2005). Furthermore, Cervero and Kockelman (1997) note that in many studies of the built environment and travel behavior, land-use variables often have little variation given one data point per neighbourhood/site, compared to most control variables (e.g., income) which are typically by person and measured on a continuous ratio scale, thus enjoying a predictive advantage.

While the literature to date provides an excellent understanding of factors affecting public transport use overall, there is a very limited understanding of how these factors vary by individual public transport mode (e.g., train, tram, bus). The research underlying this paper seeks to fill that gap using a case of Melbourne, as described in the next section.

Understanding factors affecting the use of individual public transport modes is important as there may be differential effects in the way that combinations of the built environment and mode leverage higher public transport patronage. Decision-makers wishing to choose what public transport mode is preferable when planning a new urban development need to understand how urban form, mode and patronage intersect. If, for a given level of built environment, development planners can induce a higher level of patronage by offering one mode over another, then that could influence decision making to the benefit of cities. Given the difficulty in achieving better urban outcomes, any beneficial marginal gain from differential mode selection deserves to be understood.

It is also worth highlighting that current transport and land-use planning practice tends to reflect implicit built environment and mode relationships. Development around rail stations often follows a "transit-oriented" model involving high density development within a large radial catchment. Light rail development by comparison is more likely to be used in linear boulevards where the modal characteristics of smaller scale and shorter stopping distances integrate better with high quality streetscapes. In contrast bus rapid transit is relatively uncommonly associated with built environment intensification. However, density alone is unlikely to attract sufficient ridership where development is poorly integrated with public transport. Good urban design, particularly when approached from the perspective of visual proximity, can play an important role in enhancing access and connectivity to public transport services (Loukaitou-Sideris, Higgins, Cuff, \& Oprea, 2013; Stojanovski, 2020).

\section{Research context}

This section describes the case study location of Melbourne that was chosen for this research to understand how the built environment and other characteristics affect transit use for commuting.

Melbourne is located in the southeast corner of the Australian mainland and is the capital city of the state of Victoria. During the period 2001-18, Melbourne grew from 3.5 million to 5 million people, recording an average annual growth rate of $2.1 \%$ (ABS, 2019). This represented the 57 th highest population growth rate out of 640 metropolitan areas located within countries that are part of the Organisation for Economic Co-operation and Development (OECD, 2019). By 2063, Melbourne is forecast to double in population to 10 million people, representing an expected average growth rate of $1.6 \%$ per annum (ABS, 2018).

Car ownership in Melbourne is relatively high at 593 vehicles owned per 1,000 people. This is the 6th highest car ownership rate out of 63 metropolitan areas across the world that are included in 
the UITP Mobility in Cities Database (UITP, 2015). This pattern is consistent with a relatively high proportion of commuting trips in Melbourne undertaken by car at 75\% (ABS, 2016). Public transport accounts for $18 \%$ of commuting trips, with the remainder $(7 \%)$ undertaken by other forms of transport such as walking and cycling (ABS, 2016).

An overview of Melbourne's public transport system is provided in Table 2. The system includes 17 train lines, 24 tram routes and 363 bus routes. There are also a small number of ferry services operating in Melbourne, but these are generally considered to be ancillary to the conventional public transport system (PTV, 2019a). Public transport in Melbourne is operated under a franchise agreement through private companies contracted to the Victorian state government (PTV, 2019d).

While services are operated under a franchise agreement in Melbourne, the overall network structure means passengers may have more than one public transport mode available for undertaking a trip between a given origin-destination, indicating a level of competition that exists between public transport modes. This means that we cannot simply assume that passengers are captive to a particular mode for a given journey origin-destination pair. In addition to factors such as journey time, service frequency and routing, each mode of public transport also has its own intrinsic features which make it more/less attractive to users. For example, train and trams are generally perceived as "better" modes of public transport in Melbourne due to better stop/station facilities, ease of boarding/alighting and better ride quality (Australian Transport Council, 2006).

As detailed in Table 2, and partly reflective of the large number of bus routes in Melbourne, bus services cover a far greater number of vehicle kilometres (167 million) than train or tram services (23 million and 25 million respectively). However, when ridership is considered, buses in Melbourne carry much less passengers on a per kilometre basis on average $(0.98$ passengers $/ \mathrm{km})$ than trains or trams (10.4 passengers $/ \mathrm{km}$ and 8.4 passengers $/ \mathrm{km}$ respectively). In terms of commuting to work by public transport, train services carry a much larger proportion of passengers (236,000 out of 309,000, or 76\%), than trams $(52,000$ or $17 \%)$ and buses $(21,000$ or $7 \%)$. Most tram services are located within $10 \mathrm{~km}$ of Melbourne's CBD (89.6\%), compared with train (31.5\%) and bus services (15.1\%).

Melbourne has an integrated public transport fare system, comprising of only two zones. A free tram zone also operates in the Central Business District (CBD) and free "early bird" train travel is available to passengers who exit the train network before 7:15am (PTV, 2019b). 
Table 2. Overview of Melbourne's public transport system

\begin{tabular}{|c|c|c|c|c|}
\hline Characteristic & Train & Tram & Bus & Total \\
\hline Lines/routes & 17 & 24 & 363 & 404 \\
\hline Operator & Metro Trains & Yarra Trams & Various $^{1}$ & \\
\hline Typical peak headway & 5-10 minutes & 5-10 minutes & $10-30$ minutes & \\
\hline Typical hours of operation ${ }^{2}$ & 4am-midnight & $5 \mathrm{am}-1 \mathrm{am}$ & $6 \mathrm{am}-10 \mathrm{pm}$ & \\
\hline Total annual ridership ${ }^{3}$ & 240.9 million & 206.3 million & 117.8 million & 565.0 million \\
\hline Total annual km operated ${ }^{3}$ & 23.1 million & 24.5 million & 119.8 million & 167.4 million \\
\hline Average ridership per $\mathrm{km}^{4}$ & 10.4 passengers $/ \mathrm{km}$ & 8.4 passengers $/ \mathrm{km}$ & 0.98 passengers $/ \mathrm{km}$ & 3.4 passengers $/ \mathrm{km}$ \\
\hline $\begin{array}{l}\text { Average weekday ridership for } \\
\text { commuting to work only }{ }^{5}\end{array}$ & 236,000 & 52,000 & 21,000 & 309,000 \\
\hline $\begin{array}{l}\% \text { route } \mathrm{km} \text { within } 10 \mathrm{~km} \text { of } \\
\text { Melbourne's } \mathrm{CBD}\end{array}$ & $31.5 \%$ & $89.6 \%$ & $15.1 \%$ & $26.8 \%$ \\
\hline
\end{tabular}

1 Total of 14 bus operators; key bus operators include Transdev Melbourne, Ventura Bus Lines and CDC Victoria.

2 On Fridays and Saturdays, all train services and a selection of tram and bus services operate all night.

${ }^{3}$ Figures are based on actual performance in 2017-18 for all trip purposes (including commuting).

${ }^{4}$ Calculated as annual ridership divided by annual $\mathrm{km}$ operated.

5 Figures based on the Victorian Integrated Survey of Travel and Activity (VISTA) conducted in 2018.

Sources: Department of Transport (2019b); PTV (2019c, 2019e); State of Victoria (2019).

The historical geographical development of Melbourne's public transport network also provides relevant context as it relates to the built environment. Melbourne was built around trams and trains during the 19th Century and early 20th Century, while the post-WWII period was largely built around the car and served by buses as public transport (PTV, 2012). Trams in Melbourne today tend to operate in older high-density areas as cars did not exist at the time they were introduced. The train network produced suburban "beads on a string" settlement structures with gaps between them beyond walking distance that were later filled in by car-based urban form.

To encourage land development near high quality public transport, Melbourne has a designated Principal Public Transport Network (PPTN). This comprises all metropolitan train stations and tram routes, plus a small selection of bus routes with a relatively high peak service frequency (Department of Transport, 2019a). The spatial distribution of all public transport routes in Melbourne, including the PPTN, is shown in Fig. 1.

In seeking to understand how the built environment and other characteristics affect transit use for commuting, Melbourne offers an ideal case study. The presence of integrated and multi-modal public transport system allows for factors affecting transit use to be tested separately for train, tram and bus services within the same metropolitan region. Furthermore, Melbourne represents a rapidly growing city in the developed world with a relatively high level of car dependence, particularly in new greenfield suburbs located on the urban fringe, characteristics that are considered to pose key challenges to delivering effective public transport. Using Melbourne as a case study, the method used to explore factors affecting transit use is detailed in the next section. 


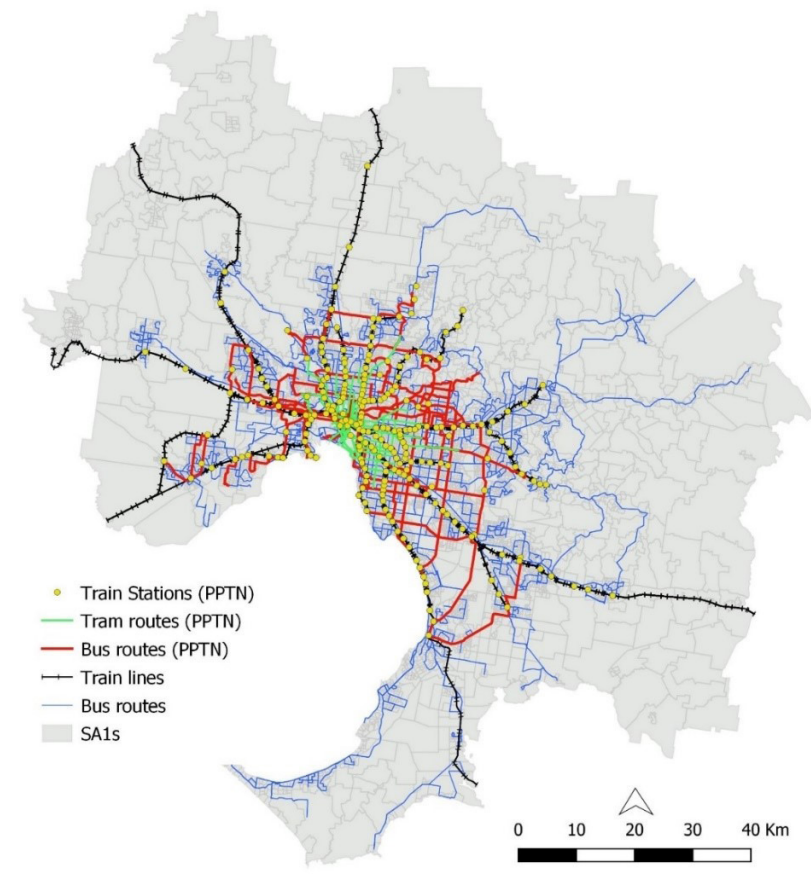

Figure 1. Spatial distribution of Melbourne's public transport network

Note: PPTN = Principal Public Transport Network; SA1s = Statistical Areas Level 1.

\section{$4 \quad$ Method}

\subsection{Compilation of dataset}

A dataset of variables was compiled based on the literature review and other factors deemed relevant as influencing public transport use. These variables are listed in Table 3, including their source and summary values. All variables were continuous and compiled for the year of 2016, in line with the last Australian census. The unit of analysis for the research was private occupied households in Statistical Areas Level 1 (SA1s) in metropolitan Melbourne. SA1s are the smallest unit of census data, with an average population of around 400 people (ABS, 2016). Metropolitan Melbourne has a total of 10,289 SA1s, thereby providing the basis for a relatively large sample size for the analysis.

Dependent variables for the analysis included the percentage of commuting trips (to work) from each SA1 undertaken by transit across all modes in total, and separately by train, tram and bus. A total of 38 independent variables were considered and classified under the 7 Ds (Ewing \& Cervero, 2010). Consistent with the literature review presented in Section 2, Distance to transit contained some non-distance related variables but were included under this category for convenience of grouping transit-related variables together. The demand management variables, while related to transit, were grouped under this category given their relationship to parking.

A key data source for the variables was the last Australian census in 2016 (ABS, 2016) which provided data for each of the dependent variables, along with the independent variables classified under density, diversity, destination accessibility and demographics. Data for the design and demand management variables was sourced from the Victorian Government's Data Directory, DataVic, an open data platform containing over 4,000 separate datasets (Victorian Government, 2019). Transit-related variables under 
the distance to transit category were sourced from the 2016 public transport network housed within the Victorian Integrated Transport Model (VITM), a strategic transport model maintained by the Victorian Government (Spiridonos, 2013).

Table 3. Variables included in the analysis

\begin{tabular}{|c|c|c|c|c|c|}
\hline Variable & Units & Source & Range & Mean & Median \\
\hline \multicolumn{6}{|l|}{ Dependent variables } \\
\hline Commuting trips by transit (all modes) ${ }^{1}$ & $\%$ & ABS census & $0-100$ & 14.3 & 12.4 \\
\hline Commuting trips by train & $\%$ & ABS census & $0-62.5$ & 10.9 & 9.5 \\
\hline Commuting trips by tram & $\%$ & ABS census & $0-100$ & 3.1 & 0.0 \\
\hline Commuting trips by bus & $\%$ & ABS census & $0-30.9$ & 2.5 & 1.6 \\
\hline \multicolumn{6}{|l|}{ Density } \\
\hline Population density & '000 people / sq. km & ABS census & $0-189.1$ & 3.3 & 2.9 \\
\hline Employment density & '000 jobs / sq. km & ABS census & $0-240.8$ & 1.3 & 0.3 \\
\hline Total population & Population & ABS census & $0-4,354$ & 435.8 & 418 \\
\hline Total dwellings & Dwellings & ABS census & $0-2,699$ & 178.2 & 164 \\
\hline Total jobs & Jobs & ABS census & $0-29,948$ & 198.5 & 57 \\
\hline \multicolumn{6}{|l|}{ Diversity } \\
\hline Non-apartment dwellings ${ }^{2}$ & $\%$ & ABS census & $0-100$ & 86.1 & 100.0 \\
\hline Jobs to population ratio & Jobs / population & ABS census & $0-7,011$ & 4.39 & 0.13 \\
\hline Land-use $\mathrm{mix}^{3}$ & n/a (entropy index) & ABS census & $0-0.67$ & 0.12 & 0.00 \\
\hline Land-use mix (excl. large scale uses) ${ }^{4}$ & n/a (entropy index) & ABS census & $0-0.86$ & 0.08 & 0.00 \\
\hline \multicolumn{6}{|l|}{ Design } \\
\hline Intersection density & Intersections / sq. km & DataVic & $0-754.7$ & 70.0 & 62.9 \\
\hline 3 -way intersections & $\%$ & DataVic & $0-100$ & 89.8 & 95.8 \\
\hline 4-way intersections & $\%$ & DataVic & $0-100$ & 11.2 & 6.7 \\
\hline Street density & Total street km / sq. km & DataVic & $0-48.3$ & 13.7 & 13.7 \\
\hline \multicolumn{6}{|l|}{ Destination accessibility } \\
\hline Distance to CBD & kilometres & GIS & $0.2-99.4$ & 25.1 & 21.8 \\
\hline Residents with distance to work $>5 \mathrm{~km}$ & $\%$ & ABS census & $0-100$ & 38.9 & 40.1 \\
\hline Residents with distance to work > $10 \mathrm{~km}$ & $\%$ & ABS census & $0-68.7$ & 28.2 & 29.1 \\
\hline \multicolumn{6}{|l|}{ Distance to transit } \\
\hline Distance to nearest train station & kilometres & VITM & $0-48.8$ & 3.2 & 2.0 \\
\hline Distance to nearest tram stop & kilometres & VITM & $0-86.9$ & 13.1 & 8.1 \\
\hline Distance to nearest bus stop & kilometres & VITM & $0-42.4$ & 1.0 & 0.5 \\
\hline Distance to nearest train station on PPTN & kilometres & VITM & $0-56.3$ & 3.8 & 2.1 \\
\hline Distance to nearest tram route on PPTN & kilometres & VITM & $0-86.9$ & 13.1 & 8.1 \\
\hline Distance to nearest bus route on PPTN & kilometres & VITM & $0-60.1$ & 4.3 & 1.4 \\
\hline Transit route density & Total route $\mathrm{m} / \mathrm{sq} . \mathrm{km}$ & VITM & $0-1,839$ & 12.1 & 2.9 \\
\hline Effective transit headway in AM peak & minutes & VITM & $0-120$ & 6.2 & 2.6 \\
\hline \multicolumn{6}{|l|}{ Demand management } \\
\hline Nearest train station with bicycle parking & kilometres & DataVic & $0-42.8$ & 3.8 & 2.2 \\
\hline Nearest train station with car parking & kilometres & DataVic & $0-42.6$ & 3.3 & 1.8 \\
\hline Car parking capacity at nearest train station & Total parking spaces & DataVic & $0-676$ & 137.0 & 92 \\
\hline
\end{tabular}




\begin{tabular}{llllll}
\hline Variable & Units & Source & Range & Mean & Median \\
\hline Demographics & & & & & \\
Persons aged 15-24 years old & $\%$ & ABS census & $0-100$ & 12.9 & 12.5 \\
Households with children & $\%$ & ABS census & $0-100$ & 46.8 & 48.8 \\
Persons with bachelor/postgraduate degree & $\%$ & ABS census & $0-100$ & 19.4 & 17.3 \\
Persons studying full-time & $\%$ & ABS census & $0-100$ & 20.4 & 20.5 \\
Persons employed full-time & $\%$ & ABS census & $0-100$ & 28.7 & 29.1 \\
Persons employed as manager/professional & $\%$ & ABS census & $0-100$ & 17.6 & 16.7 \\
Male persons & $\%$ & ABS census & $0-100$ & 48.3 & 49.1 \\
Average household car ownership & Cars / household & ABS census & $0-3.60$ & 1.62 & 1.65 \\
Average household size & Persons / household & ABS census & $0-381.7$ & 2.56 & 2.56 \\
Non-renting households & $\%$ & ABS census & $0-100$ & 65.4 & 69.8 \\
Households with income above median & $\%$ & ABS census & $0-100$ & 54.4 & 56.3 \\
\hline
\end{tabular}

Note: $\mathrm{ABS}=$ Australian Bureau of Statistics; DataVic = Victorian Government Data Directory; GIS = Geographic Information System; PPTN = Principal Public Transport Network; VITM = Victorian Integrated Transport Model.

1 All commuting trips by train, tram and bus; value is less than the sum of individual modes due to use of multiple modes.

2 Includes separate houses, semi-detached houses, row/terrace houses and townhouses.

3 Entropy index calculated based on the balance between the following ten land uses in each SA1: residential, commercial, industrial, education, parkland, hospital/medical, transport, water, other, primary production; ranges from 0 where all land in the SA1 is a single use, to 1 where land is evenly divided among all land uses.

${ }^{4}$ Large scale land uses excluded in calculation of entropy index: parkland, water, primary production.

5 Median weekly household income in 2016 was $\$ 1,542$.

While identified through the literature review as influencing transit use, transit fare levels were not included as a variable in this research. This was due to the lack of variation in fare levels across Melbourne, with only two main zones across the entire metropolitan area (PTV, 2019b). While the free tram zone operates in the $\mathrm{CBD}$, this was of less relevance as it is located at the destination end of commuting trips to the $\mathrm{CBD}$. Other variables such as fuel prices, which can also influence transit use, were not incorporated due to their lack of spatial variability across the metropolitan area. As noted by Cervero and Kockelman (1997), variables at the person (or even household) level tend to enjoy a predictive advantage in travel behavior studies due to greater variability.

\subsection{Data analysis}

Following the compilation of all variables for each SA1, simple bivariate comparisons were first undertaken to explore the association between public transport commuting and each independent (continuous) variable. Pearson correlation coefficients were calculated to indicate the strength of the association between each independent variable and public transport commuting, while testing for statistical significance using a t-test. Independent variables with a high level of correlation were then plotted against the percentage of commuting trips by transit, using discrete intervals for ease of interpretation. All bivariate comparisons were undertaken separately for each public transport mode and in total across all modes (train, tram, bus).

Following the bivariate analysis, multivariate modelling was undertaken to further explore factors associated with public transport commuting. Regression models were estimated separately to predict the percentage of commuting trips undertaken by public transport in total and the percentage undertaken by each mode (train, tram, bus) for each SA1. All variables were analysed as continuous variables. To explore spatial variability in the associations, separate models were also estimated for the inner metro- 
politan area (distance to $\mathrm{CBD}<10 \mathrm{~km}$ ) and outer metropolitan area (distance to $\mathrm{CBD}>10 \mathrm{~km}$ ). As the values of each dependent ranged from 0 to 1 (i.e. percentages), both ordinary least squares (OLS) and beta regression models were employed, in line with recommended practice from Kieschnick and McCullough (2003). The OLS model specification is:

$$
Y_{i}=\beta_{0}+\beta_{1} B E_{i}+\beta_{2} \text { Service }_{i}+\beta_{3} S D_{i}+{ }_{\varepsilon i}
$$

where $Y_{-} i$ is the percentage of commuting trips (to work) from each SA1 undertaken by transit across all modes in total, and separately by train, tram and bus; $B E_{i}$, Service ${ }_{i}$, and $S D_{i}$ represent built environment, transit service, and socio-demographic variables respectively; $\beta_{0}$ is a constant; $\beta_{1}, \beta_{2}, \beta_{3}$ are the coefficients to be estimated; $\varepsilon_{i}$ is the error term.

For beta regression, we followed Ferrari and Cribari-Neto (2004) to specify the model as follows:

$$
g\left(\mu_{i}\right)=\log \frac{\mu_{i}}{1-\mu_{i}}=x_{i}^{T} \beta
$$

where $\mu_{i} \in(0,1)$ denotes the expected value of $Y_{i} ; \mathrm{g}(\mathrm{i})$ is a link function that is strictly monotonic and twice differentiable; $X_{i}^{T}$ denotes a set of independent variables.

For all OLS models estimated, robust standard errors were used to correct for possible bias from heteroscedasticity. Variance Inflation Factors (VIFs) were also derived to detect potential multicollinearity in variables. After removing variables that were likely to exhibit multicollinearity, the VIFs in all models were less than 3.0, indicating no concerns for multicollinearity (Allison, 1999). Variables that were not statistically significant were excluded from the analysis. However, if a variable was significant in one model, it was retained in the other models for comparison purposes. Results from the OLS and beta regression models were relatively similar in terms of coefficient signs and levels of significance, so results from the OLS models were reported for ease of interpreting coefficients. All models were estimated using Stata/MP 14.0.

\section{$5 \quad$ Results}

This section of the paper details the results of the analysis. Bivariate comparisons are presented first to explore the association between commuting by transit and each independent variable. Results of the regression analysis are then presented to better understand how the built environment and other characteristics affect transit use for commuting by mode, specifically train, tram and bus services.

\subsection{Bivariate analysis}

Table 4 details the strength of the association between each independent variable and public transport commuting (by mode and in total), using Pearson correlation coefficients.

With the exception of 3-way intersections, all independent variables have a statistically significant association with public transport commuting in total (across all modes). Independent variables with a relatively high correlation include persons with bachelor/postgraduate degree (0.70), distance to $C B D$ $(-0.65)$, distance to nearest tram stop / route (on PPTN) (-0.57), persons employed as manager/professional $(0.50)$ and distance to nearest train station (on PPTN) $(-0.41)$. The signs of all correlation coefficients are as expected and consistent with the literature. 
For commuting by train, results are similar to commuting by all transit modes, albeit containing weaker associations with each independent variable. Here, independent variables with a relatively high correlation include persons with bachelor/postgraduate degree (0.47), distance to $C B D(-0.46)$ and distance to nearest tram stop / route (on PPTN) (-0.43). It is noted that distance to the nearest train station has a weaker association than distance to the nearest tram stop / route $(-0.37 /-0.38$ for train vs. -0.43 for tram). This may reflect a geographical difference as tram services are more concentrated within the inner city where car ownership is lower and the propensity to use public transport is generally higher. It is also noted that in addition to 3-way intersections not being statistically significant, residents with distance to work $>10 \mathrm{~km}$, households with children and average household size are also not statistically significant for commuting by train.

For commuting by tram, all independent variables have a statistically significant association with the exception of jobs to population ratio and male persons. Independent variables with a relatively high correlation include persons with bachelor/postgraduate degree (0.56), non-apartment dwellings (-0.51), distance to $C B D(-0.46)$, residents with distance to work $>10 \mathrm{~km}(-0.46)$, persons employed as manager/professional $(0.45)$ and households with children $(-0.41)$. It is noted that some of these associations are stronger than for public transport commuting in total (all modes) which may reflect the concentrated inner city location of the tram network relative to train and bus.

For commuting by bus, associations with each independent variable tend to be the weakest out of all public transport modes. The strongest associations are found with distance to $C B D(-0.25)$, distance to nearest tram stop / route (on PPTN) (-0.25), and distance to nearest bus stop on PPTN (-0.23). In addition, a number of independent variables are not statistically significant, including: employment density, total jobs, land-use mix, residents with distance to work $>5 \mathrm{~km}$ and average household size. This suggests that there are likely to be other factors that influence bus use for commuting that are not captured by the analysis. 
Table 4. Pearson correlation coefficients ( $r$ ) between independent variables and commuting trips by transit

\begin{tabular}{|c|c|c|c|c|c|c|c|c|}
\hline Variable & Total & & Train & & Tram & & Bus & \\
\hline Density & 0.34 & $* * *$ & 0.12 & $* * *$ & 0.40 & $* * *$ & 0.07 & *** \\
\hline Employment density & 0.23 & $* * *$ & 0.03 & $* * *$ & 0.34 & $* * *$ & 0.01 & \\
\hline Total population & 0.24 & $* * *$ & 0.19 & $* * *$ & 0.15 & $* * *$ & 0.11 & *** \\
\hline Total dwellings & 0.36 & $* * *$ & 0.20 & $* * *$ & 0.33 & $* * *$ & 0.11 & $* * *$ \\
\hline Total jobs & 0.08 & $* * *$ & -0.03 & $* * *$ & 0.16 & $* * *$ & -0.01 & \\
\hline \multicolumn{9}{|l|}{ Diversity } \\
\hline Non-apartment dwellings & -0.37 & $* * *$ & -0.12 & $* * *$ & -0.51 & $* * *$ & -0.02 & * \\
\hline Jobs to population ratio & -0.06 & $* * *$ & -0.06 & $* * *$ & -0.01 & & -0.03 & $* * *$ \\
\hline Land-use mix & 0.09 & $* * *$ & 0.05 & $* * *$ & 0.08 & $* * *$ & 0.00 & \\
\hline Land-use mix (excl. large scale uses) & 0.22 & $* * *$ & 0.14 & $* * *$ & 0.19 & $* * *$ & 0.05 & *** \\
\hline \multicolumn{9}{|l|}{ Design } \\
\hline Intersection density & 0.35 & $* * *$ & 0.20 & $* * *$ & 0.32 & $* * *$ & 0.09 & *** \\
\hline 3 -way intersections & -0.01 & & -0.01 & & -0.02 & $* *$ & 0.06 & *** \\
\hline 4-way intersections & 0.23 & $* * *$ & 0.10 & $* * *$ & 0.25 & $* * *$ & 0.07 & *** \\
\hline Street density & 0.39 & *** & 0.24 & $* * *$ & 0.33 & $* * *$ & 0.14 & *** \\
\hline \multicolumn{9}{|l|}{ Destination accessibility } \\
\hline Distance to CBD & -0.65 & $* * *$ & -0.46 & $* * *$ & -0.46 & $* * *$ & -0.25 & *** \\
\hline Residents with distance to work $>5 \mathrm{~km}$ & 0.02 & ** & 0.21 & $* * *$ & -0.21 & $* * *$ & 0.00 & \\
\hline Residents with distance to work $>10 \mathrm{~km}$ & -0.29 & $* * *$ & -0.01 & & -0.46 & $* * *$ & -0.05 & *** \\
\hline \multicolumn{9}{|l|}{ Distance to transit } \\
\hline Distance to nearest train station & -0.41 & $* * *$ & -0.37 & $* * *$ & -0.19 & $* * *$ & -0.14 & *** \\
\hline Distance to nearest tram stop & -0.57 & $* * *$ & -0.43 & $* * *$ & -0.36 & $* * *$ & -0.25 & *** \\
\hline Distance to nearest bus stop & -0.19 & $* * *$ & -0.15 & $* * *$ & -0.10 & $* * *$ & -0.13 & *** \\
\hline Distance to nearest train station on PPTN & -0.41 & $* * *$ & -0.38 & $* * *$ & -0.18 & $* * *$ & -0.16 & *** \\
\hline Distance to nearest tram route on PPTN & -0.57 & $* * *$ & -0.43 & $* * *$ & -0.36 & $* * *$ & -0.25 & *** \\
\hline Distance to nearest bus route on PPTN & -0.38 & $* * *$ & -0.32 & $* * *$ & -0.18 & $* * *$ & -0.23 & *** \\
\hline Transit route density & 0.26 & $* * *$ & 0.18 & $* * *$ & 0.20 & $* * *$ & 0.04 & $* * *$ \\
\hline Effective transit headway in AM peak & -0.19 & $* * *$ & -0.13 & $* * *$ & -0.14 & $* * *$ & -0.10 & *** \\
\hline \multicolumn{9}{|l|}{ Demand management } \\
\hline Nearest train station with bicycle parking & -0.37 & $* * *$ & -0.38 & $* * *$ & -0.12 & $* * *$ & -0.15 & $* * *$ \\
\hline Nearest train station with car parking & -0.35 & $* * *$ & -0.36 & $* * *$ & -0.12 & $* * *$ & -0.14 & $* * *$ \\
\hline Car parking capacity at nearest train station & -0.21 & $* * *$ & -0.08 & $* * *$ & -0.22 & $* * *$ & -0.08 & *** \\
\hline \multicolumn{9}{|l|}{ Demographics } \\
\hline Persons aged $15-24$ years old & 0.20 & $* * *$ & 0.08 & $* * *$ & 0.20 & $* * *$ & 0.11 & *** \\
\hline Households with children & -0.25 & $* * *$ & -0.01 & & -0.41 & $* * *$ & -0.03 & *** \\
\hline Persons with bachelor/postgraduate degree & 0.70 & $* * *$ & 0.47 & $* * *$ & 0.56 & $* * *$ & 0.18 & *** \\
\hline Persons studying full-time & 0.15 & $* * *$ & 0.14 & $* * *$ & 0.03 & $* * *$ & 0.12 & *** \\
\hline Persons employed full-time & 0.28 & $* * *$ & 0.19 & $* * *$ & 0.26 & $* * *$ & -0.04 & *** \\
\hline Persons employed as manager/professional & 0.50 & $* * *$ & 0.32 & $* * *$ & 0.45 & $* * *$ & 0.02 & ** \\
\hline Male persons & 0.10 & $* * *$ & 0.11 & $* * *$ & 0.02 & & 0.07 & *** \\
\hline Average household car ownership & -0.37 & $* * *$ & -0.18 & $* * *$ & -0.39 & $* * *$ & -0.11 & $* * *$ \\
\hline
\end{tabular}




\begin{tabular}{lccccccccc}
\hline Variable & Total & & Train & \multicolumn{1}{c}{ Tram } & \multicolumn{3}{c}{ Bus } \\
\hline Average household size & -0.04 & $* * *$ & -0.01 & & -0.04 & $* * *$ & 0.00 & \\
Non-renting households & -0.37 & $* * *$ & -0.17 & $* * *$ & -0.40 & $* * *$ & -0.13 & $* * *$ \\
Households with income above median & 0.12 & $* * *$ & 0.13 & $* * *$ & 0.04 & $* * *$ & -0.06 & $* * *$ \\
\hline
\end{tabular}

Note: ${ }^{* * *} \mathrm{p}<0.01,{ }^{* *} \mathrm{p}<0.05,{ }^{*} \mathrm{p}<0.10$

Based on the above findings, independent variables with a high level of correlation (persons with bachelor/postgraduate degree, distance to CBD and distance to nearest train/tram/bus on PPTN) are plotted against the percentage of commuting trips by transit in Fig. 2 to Fig. 4. While having a weaker association with public transport commuting, effective transit headway in $A M$ peak is also shown in Fig. 5 given its role in supporting public transport ridership. The bivariate relationships are as expected, with public transport commuting increasing as persons with bachelor/ postgraduate degree increases (Fig. 2) and declining as the other independent variables increase. Commuting by tram, and to a lesser extent bus, appear to be more sensitive to changes in the independent variables than commuting by train. For distance to $C B D$ (Fig. 3), bus use tends to be highest for distances approximately $10-25 \mathrm{~km}$ from the CBD, while tram use is highest for distances less than $10 \mathrm{~km}$ from the $\mathrm{CBD}$, thereby reflecting the geographical coverage of these services.

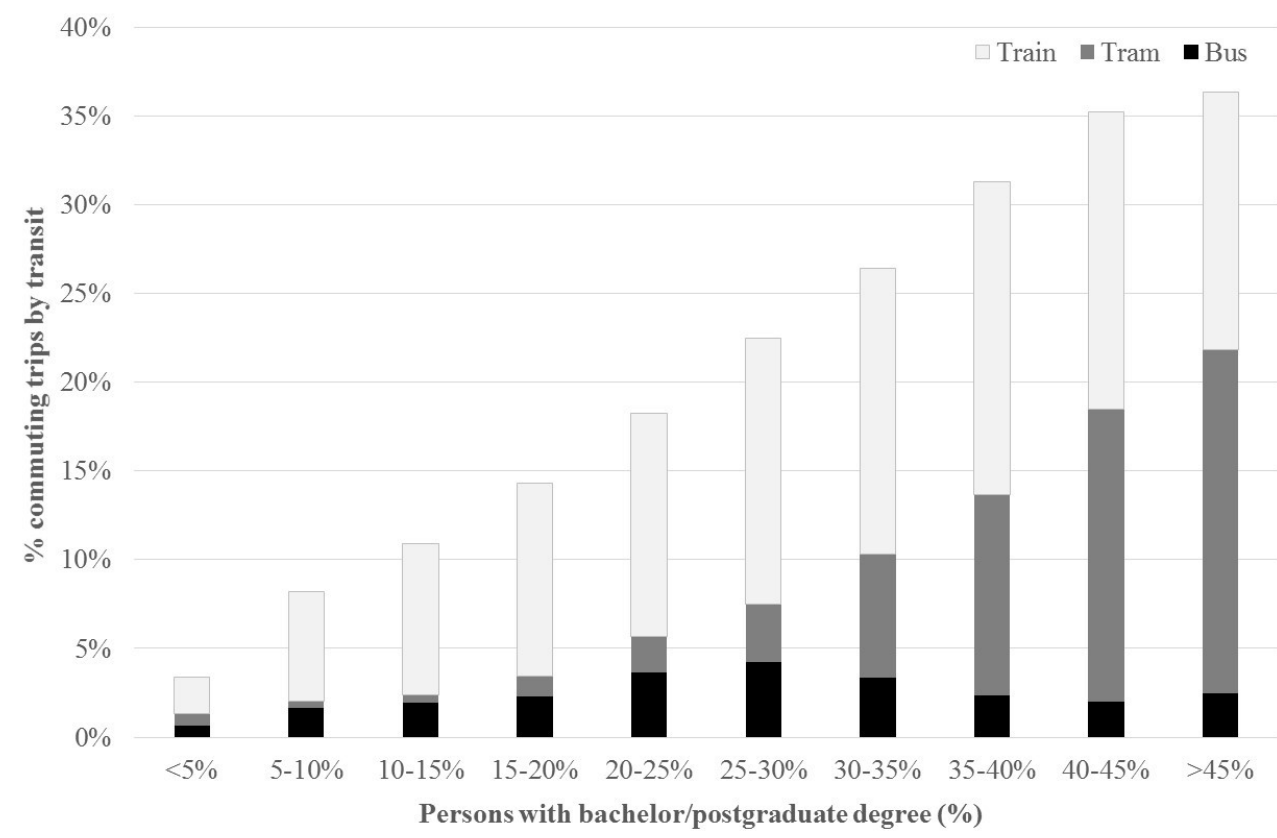

Figure 2. Persons with bachelor/postgraduate degree vs. commuting trips by transit

Note: Unit of analysis is Statistical Areas Level 1 (SA1s), the smallest available unit of census data. 


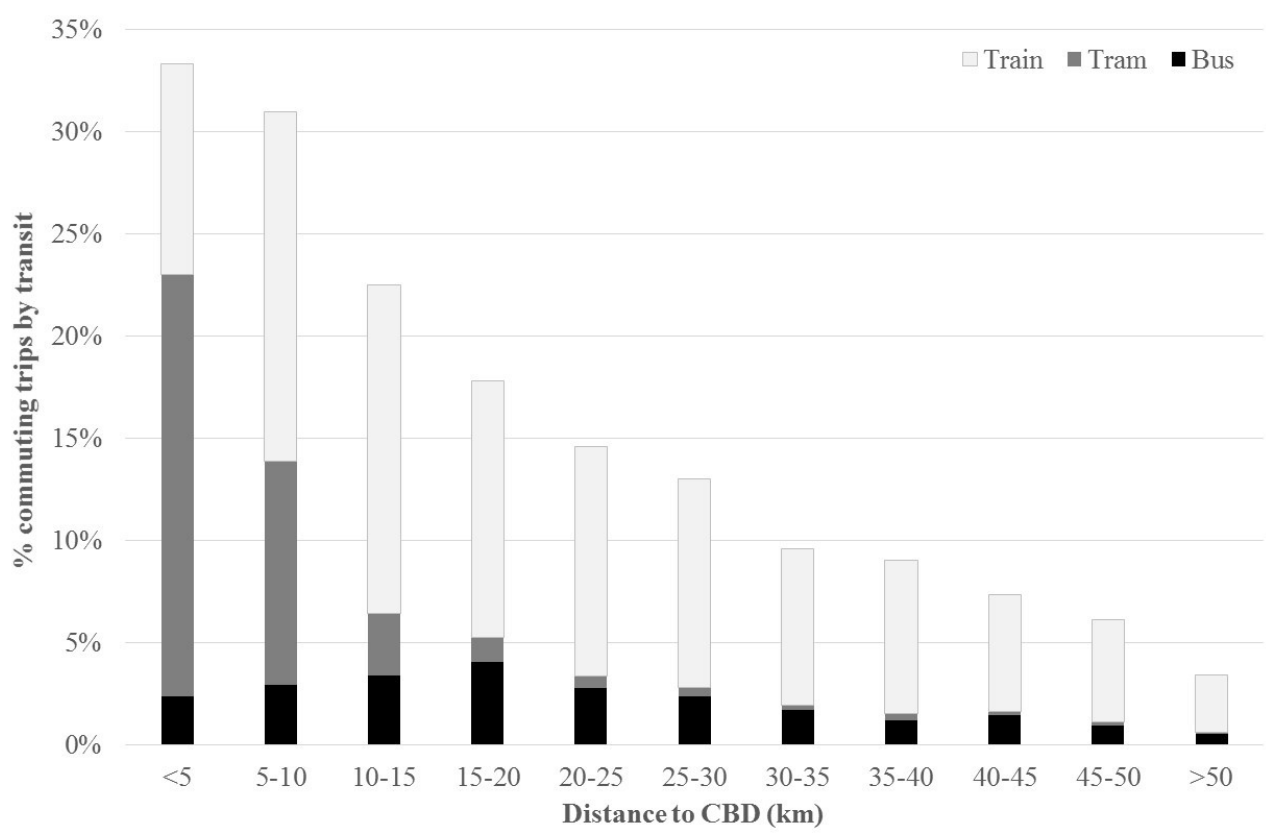

Figure 3. Distance to CBD vs. commuting trips by transit

Note: Unit of analysis is Statistical Areas Level 1 (SA1s), the smallest available unit of census data.

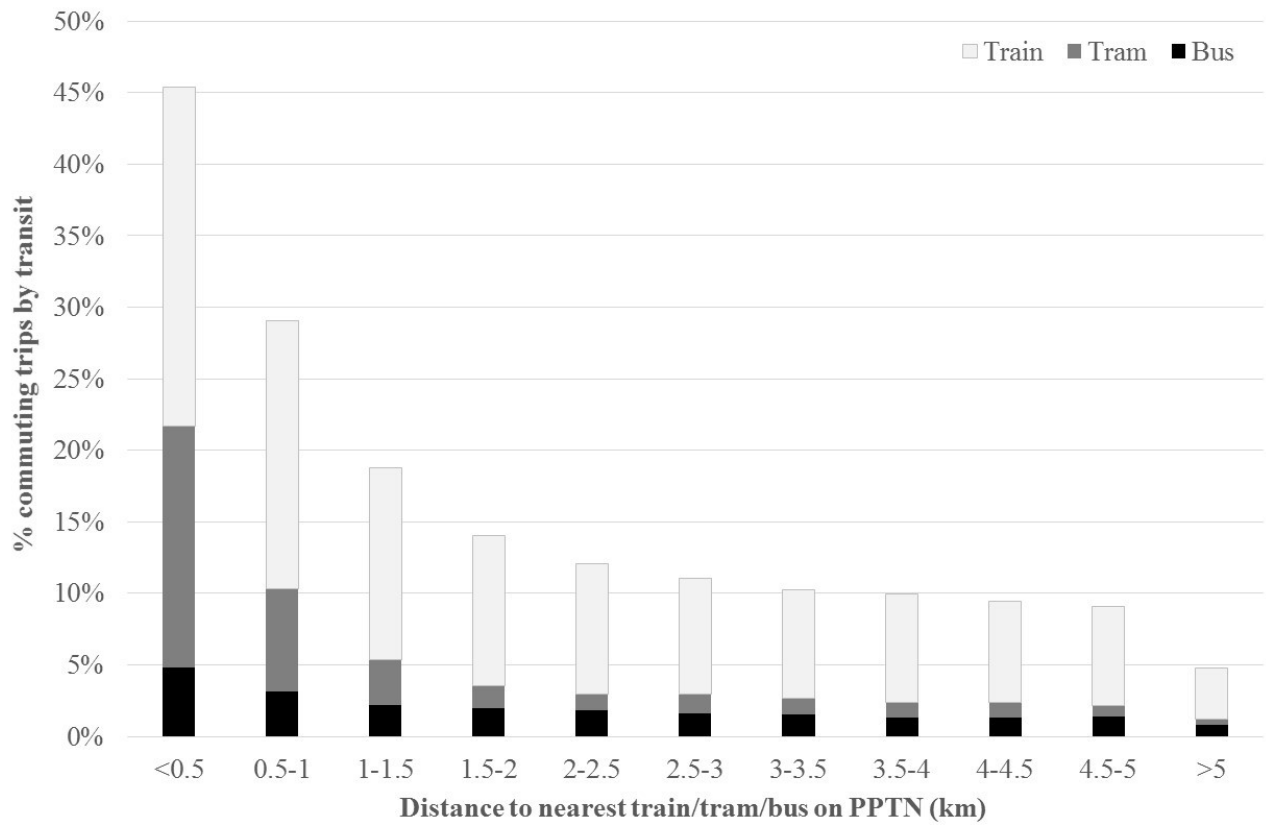

Figure 4. Distance to nearest train/tram/bus on PPTN vs. commuting trips by transit Note: Unit of analysis is Statistical Areas Level 1 (SA1s), the smallest available unit of census data. 


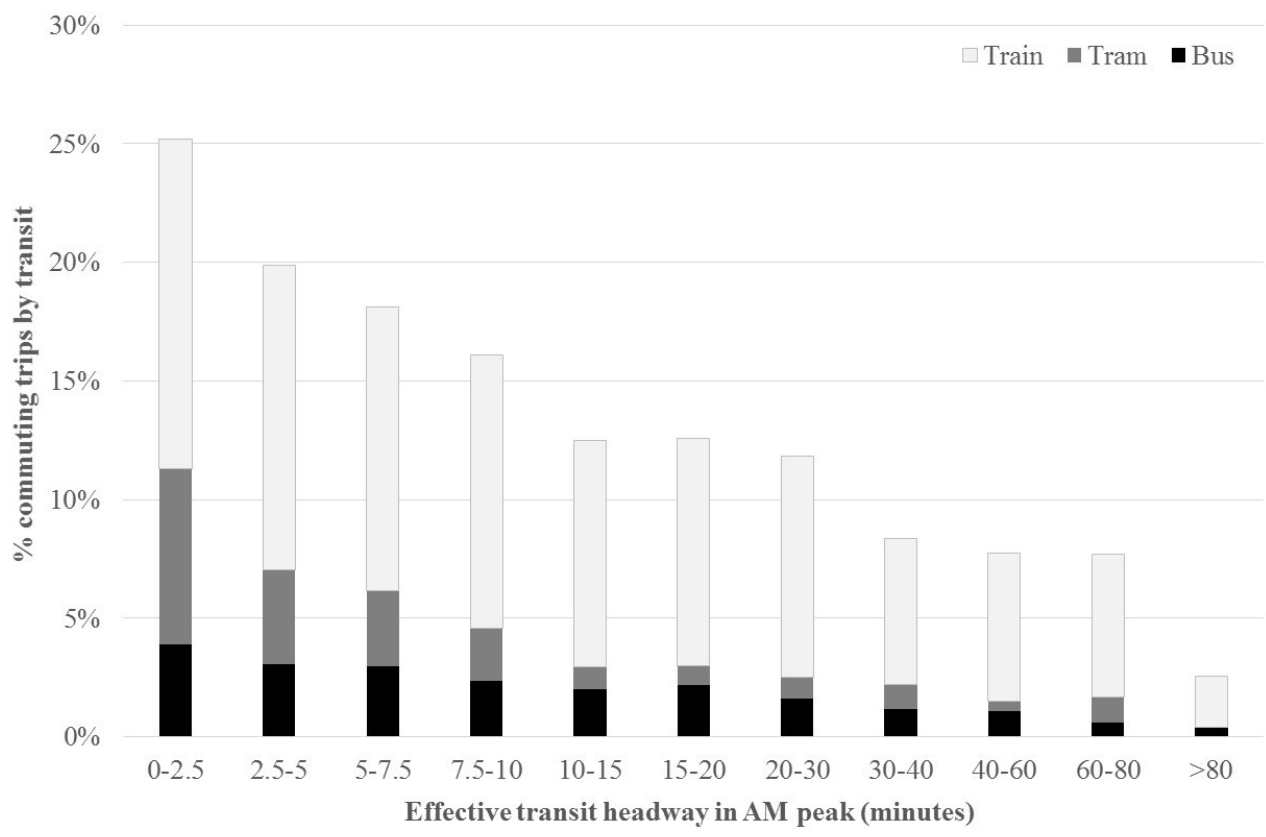

Figure 5. Effective transit headway in AM peak vs. commuting trips by transit.

Note: Unit of analysis is Statistical Areas Level 1 (SA1s), the smallest available unit of census data.

\subsection{Regression analysis}

Table 5 details the results of the regression analysis for all of metropolitan Melbourne, separately by each public transport mode and in total (across all modes). For ease of comparing results across modes, the description of results is structured in line with the 7 Ds, with the exception of Demand management variables which were not significant. In describing the results, regression coefficients are quoted (in parentheses) where relevant to indicate the strength of the association of independent variables with public transport commuting. Firstly though, it is worth noting that all models have relatively high explanatory power ( $\mathrm{R}^{2}$ ranging from 0.40 to 0.69$)$, with the exception of the bus only model $\left(\mathrm{R}^{2}=0.14\right)$. The weaker prediction for bus indicates that there are likely to be other factors not captured by the analysis that better explain commuting by this mode. This may include, but is not necessarily limited to, attributes specific to the destination end of bus commuting trips. It is also worth noting that the results of the regression analysis are not always consistent with the results from the bivariate analysis, primarily due to correlations between independent variables in the regression analysis. Further, regression analysis presents the net effect of each built environment variable after accounting for other built environment, transit service and socio-demographic variables, while the bivariate analysis shows simple correlations without controlling for other variables.

For the Density variables, population density, employment density and total dwellings were all significant in each model. Population density had the strongest (positive) association with commuting by tram (0.0016) but had a negative association with commuting by train $(-0.0008)$ and bus $(-0.0002)$. Employment density also had a negative association with train (-0.00013) and bus ( 0.0003), compared to a positive association with tram (0.0009). These results highlight the concentration of tram services in higher density environments in Melbourne, compared to train and bus services. As expected, total dwellings were positively associated with public transport commuting by each mode. Across all public transport modes, the results suggest that an increase in population density of 10,000 people/sq. $\mathrm{km}$ is associated with a modest 0.005 percentage point increase in public transport commuting, while an in- 
crease in employment density of 10,000 jobs/sq. $\mathrm{km}$ is associated with a 0.003 percentage point decrease in public transport commuting. As the unit of analysis is at the household level, these results are intuitive as residents living in areas of high employment density generally have greater opportunity to also work in the same area which is likely to be associated with lower public transport use due to higher levels of walking/cycling to work. For population density, the results are also intuitive as train and bus services tend to operate in lower density environments than trams.

For the Diversity variables, jobs to population ratio had a very small but significant association with commuting by each public transport mode. Land-use mix had a stronger association, particularly for train (0.0299), but was not significant for bus as these services tend to operate in lower density environments with greater homogeneity in land use (e.g., residential). Across all public transport modes, a 10 percentage point increase in land-use mix is associated with a 0.37 percentage point increase in public transport commuting.

Under Design, 4-way intersections were positively associated with commuting by each mode, except by train which was not significant. The strongest association was found with tram (0.0198), consistent with its presence in higher density, more walkable environments. Across all public transport modes, a 10 percentage point increase in 4-way intersections is associated with a 0.17 percentage point increase in public transport commuting.

For the Destination accessibility variables, distance to $C B D$ had an expected negative association with public transport commuting, implying that commuting by public transport decreases with distance from the CBD. This variable was not included for tram as these services are concentrated mostly within a $10 \mathrm{~km}$ radius of the CBD. Residents with distance to work $>10 \mathrm{~km}$ had a positive association with public transport commuting, particularly for train (0.2041) but a negative association with commuting by tram given the shorter routes generally offered by this mode. Across all public transport modes, a 10 percentage point increase in residents with a distance to work of more than $10 \mathrm{~km}$ is associated with a 0.84 percentage point increase in public transport commuting.

For the Distance to transit variables, distance to nearest train station / bus route on PPTN was negatively associated with commuting by train and bus respectively, as expected. However, distance to nearest tram route on PPTN was not significant in explaining commuting by tram, potentially reflecting an already sufficiently dense network of tram routes in the inner area. This is consistent with the lack of statistical significance of transit route density for tram, but a significant association with commuting by train and bus. Effective transit headway in $A M$ peak was negatively associated with commuting by tram and bus, as expected, but was not significant for train. This result may be explained by a lack of variability in train service frequencies in the AM peak.

In terms of Demographics, results are generally in line with expectations. Consistent with the results of the bivariate analysis, persons with bachelor/postgraduate degree had a strong positive association with public transport commuting, particularly by train (0.3563) but less so for tram (0.0984) and bus (0.1051). Average household car ownership was negatively associated with public transport commuting, particularly by train $(-0.0540)$ but less so for tram $(-0.0137)$ and bus ( 0.0074). Across all public transport modes, a 10 percentage point increase in average household car ownership is associated with a 0.59 percentage point decrease in public transport commuting. 
Table 5. Regression coefficients for commuting by transit for all of metropolitan Melbourne

\begin{tabular}{|c|c|c|c|c|c|c|c|c|}
\hline Variable (units) & Total & & Train & & Tram & & Bus & \\
\hline Constant & 0.0793 & $* * *$ & 0.0607 & $* * *$ & 0.0016 & $* * *$ & 0.0171 & *** \\
\hline Density & & & & & 0.0009 & $* * *$ & & \\
\hline Population density ('000 people / sq. km) & 0.0005 & $* *$ & -0.0008 & $* * *$ & 0.0001 & $* * *$ & -0.0002 & *** \\
\hline Employment density ('000 jobs / sq. km) & -0.0003 & $* *$ & -0.0013 & $* * *$ & & & -0.0003 & *** \\
\hline Total dwellings (dwellings) & 0.0001 & $* * *$ & 0.0001 & $* * *$ & 0.0000 & $* *$ & 0.0000 & *** \\
\hline Diversity & & & & & 0.0094 & ** & & \\
\hline Jobs to population ratio (jobs / population) & -0.0001 & $* * *$ & 0.0000 & ** & & & 0.0000 & * \\
\hline Land-use mix (excl. large scale uses) & 0.0366 & $* * *$ & 0.0299 & $* * *$ & 0.0198 & $* * *$ & 0.0016 & \\
\hline \multicolumn{9}{|l|}{ Design } \\
\hline 4-way intersections (\%) & 0.0169 & $* * *$ & -0.0037 & & & & 0.0065 & *** \\
\hline Destination accessibility & & & & & -0.1387 & $* * *$ & & \\
\hline Distance to CBD $(\mathrm{km})$ & -0.0018 & $* * *$ & -0.0012 & $* * *$ & & & -0.0003 & *** \\
\hline Residents with distance to work > $10 \mathrm{~km}(\%)$ & 0.0843 & $* * *$ & 0.2041 & $* * *$ & & & 0.0348 & *** \\
\hline Distance to transit & & & & & 0.0000 & & & \\
\hline Distance to nearest train station on PPTN $(\mathrm{km})$ & -0.0012 & $* * *$ & -0.0014 & $* * *$ & & & & \\
\hline Distance to nearest tram route on PPTN $(\mathrm{km})$ & & & & & 0.0000 & & & \\
\hline Distance to nearest bus route on PPTN $(\mathrm{km})$ & & & & & -0.0001 & $* * *$ & -0.0004 & *** \\
\hline Transit route density (total route $\mathrm{m} / \mathrm{sq} . \mathrm{km}$ ) & 0.0002 & $* * *$ & 0.0002 & $* * *$ & & & 0.0000 & $*$ \\
\hline Effective transit headway in AM peak (mins) & -0.0001 & $* *$ & 0.0000 & & -0.0916 & $* * *$ & -0.0001 & *** \\
\hline Demographics & & & & & 0.0984 & $* * *$ & & \\
\hline Households with children (\%) & -0.0463 & $* * *$ & 0.0396 & $* * *$ & 0.1910 & $* * *$ & -0.0110 & ** \\
\hline Persons with bachelor/postgraduate degree (\%) & 0.4269 & $* * *$ & 0.3563 & $* * *$ & 0.1605 & $* * *$ & 0.1051 & *** \\
\hline Persons studying full-time (\%) & 0.1653 & $* * *$ & -0.0069 & & 0.0548 & $* *$ & 0.0340 & *** \\
\hline Persons employed full-time (\%) & 0.0802 & $* * *$ & -0.0321 & * & -0.0015 & & -0.0352 & *** \\
\hline Persons employed as manager/professional (\%) & -0.1191 & $* * *$ & -0.1434 & $* * *$ & -0.0137 & $* * *$ & -0.1086 & *** \\
\hline Male persons (\%) & 0.1243 & $* * *$ & 0.1076 & $* * *$ & 10,289 & & 0.0479 & *** \\
\hline Average household car ownership (cars/household) & -0.0592 & $* * *$ & -0.0540 & $* * *$ & 0.55 & & -0.0074 & *** \\
\hline Number of observations (n) & 10,289 & & 10,289 & & 0.55 & & 10,289 & \\
\hline R-squared (R2) & 0.69 & & 0.40 & & & & 0.14 & \\
\hline Adjusted R-squared (adj. R2) & 0.69 & & 0.40 & & & & 0.14 & \\
\hline
\end{tabular}

Note: ${ }^{* * *} \mathrm{p}<0.01,{ }^{* *} \mathrm{p}<0.05,{ }^{*} \mathrm{p}<0.10$

Overall, the regression analysis has highlighted how factors associated with public transport commuting can vary by mode, both in terms of the factors themselves and their relative influence. In particular, the findings point to specific differences for commuting by tram, for which services are generally focused within a $10 \mathrm{~km}$ radius of Melbourne's CBD. For this reason, a second set of regression analyses were undertaken, separately for inner metropolitan Melbourne ( $<10 \mathrm{~km}$ from CBD) and outer metropolitan Melbourne (>10 km from CBD). The results are detailed in Table 6.

This shows that, when separated by location, most built environment variables have a weaker association with public transport commuting (due to greater homogeneity in the built environment) while distance to nearest train / tram / bus on PPTN has a stronger association within inner Melbourne. This highlights the relative influence of the built environment across a metropolitan scale, compared to the more localised influence of public transport service provision. 


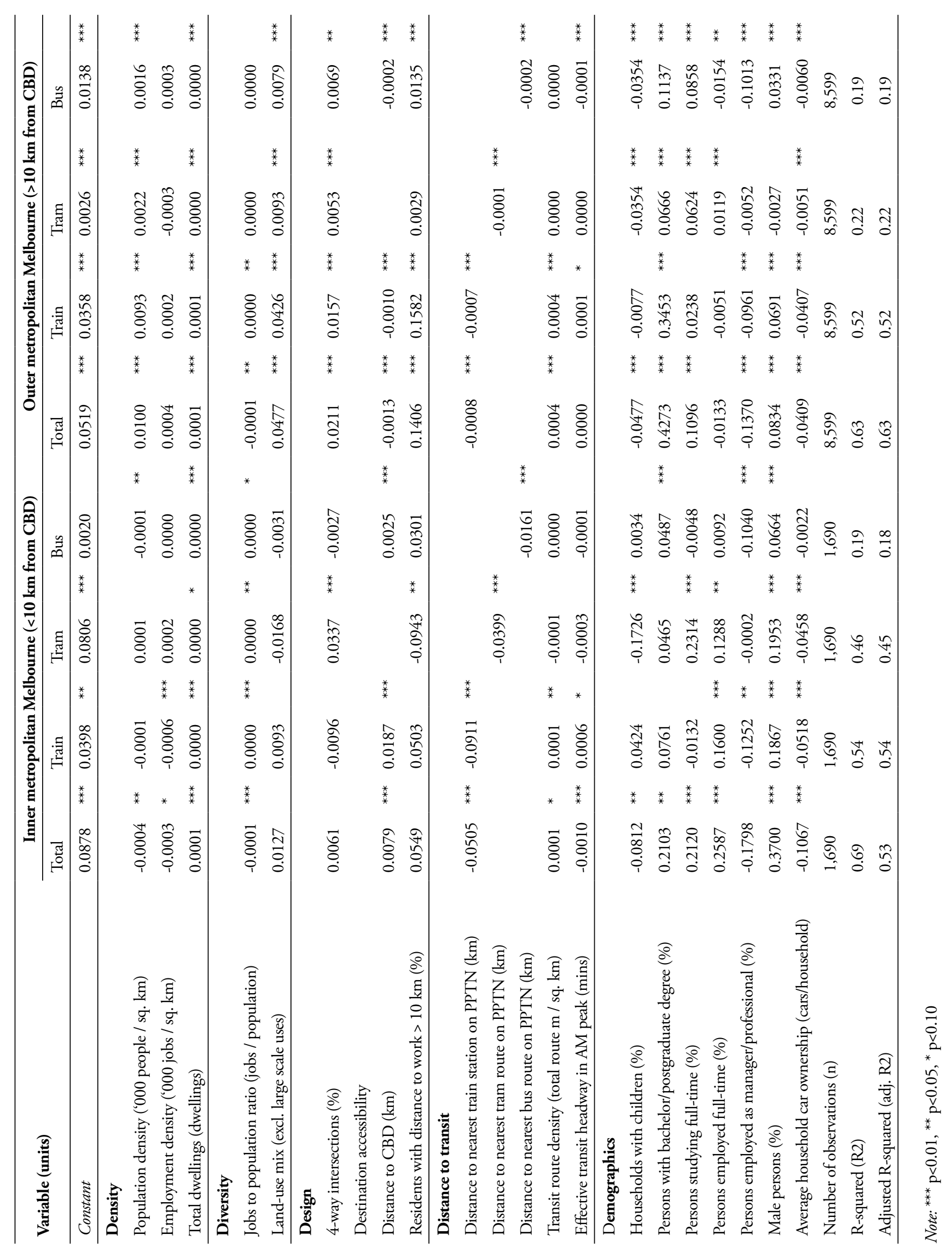




\section{Discussion and conclusion}

Using a case study of Melbourne, the aim of this research was to understand how the built environment and other characteristics affect transit use for commuting (to work) by mode, specifically train, tram and bus. Results of the analysis showed that the built environment has a significant influence, but with notable differences between individual public transport modes.

Commuting by tram was found to have the strongest association with the explanatory variables, while bus had the weakest explanatory power. Differences in the geographical coverage of public transport services in Melbourne play a key role in explaining the influence of the built environment. For example, population density is positively associated with tram use (as this mode operates in higher density environments) but is negatively associated with train and bus use. Furthermore, the association between land-use mix and public transport commuting is only significant for train and tram use as bus services tend to operate in environments with greater land-use homogeneity. When the analysis was limited to inner Melbourne only $(<10 \mathrm{~km}$ from the $\mathrm{CBD})$, where tram services predominantly operate, the influence of the built environment is diluted, while distance to public transport becomes more significant. Socio-demographics were also found to play a key role in explaining public transport commuting. In particular, a greater proportion of people with a bachelor/postgraduate degree and lower household car ownership were associated with higher levels of public transport commuting, with these effects being strongest for train use.

In comparing the findings back to the literature, this study reports a range of factors associated with public transport use that are consistent with previous research (Boulange et al., 2017; Cervero, 1994; Chow et al., 2006; Ewing \& Cervero, 2010; Taylor et al., 2009). An exception to this is income which was not reported to be significant in this study, compared to previous research (Dill, Schlossberg, Ma, \& Meyer, 2013; McKibbin, 2011; Renne et al., 2016; Taylor et al., 2009; Tsai et al., 2012). This may be due to the focus on public transport commuting, rather than public transport use for all trip purposes. In Melbourne, public transport commuting is largely undertaken by train (as shown earlier in Table 2) which has a radial network that is directed towards the CBD. As a key centre of employment, the CBD also has high car parking costs which deter car use. This study also found that the effects of the built environment become diluted when focusing on inner Melbourne where the tram network is predominately located. This is consistent with the findings of Arrington and Cervero (2008) who noted that "factors like mixed land uses, traffic calming, pedestrian amenities, and even density seem to matter little" when commuters live close to transit.

Perhaps the most notable finding of this study, compared with previous research, is how factors associated with public transport commuting can vary by mode, not only in terms of the factors themselves but also their relative influence. Despite the implications of these findings for practice, this has not been a large focus of previous research. A mode-specific approach towards increasing transit ridership may therefore prove more effective than a blanket (all-mode) approach, given the inherent differences that exist in factors that influence ridership by mode.

Using the results of this study, it may be possible to better account for factors that influence the use of different public transport modes in transit demand forecasting models, while noting the intrinsic link between the built environment and the geographical coverage of public transport services. The results of this research can also be useful for planning new public transport services, particularly in new greenfield developments, where proposed features of the built environment (including public transport characteristics) can be used to help inform decision making on the type/s of public transport modes to be introduced. Here, the segmented model results provided earlier in Table 6 may be useful when focusing on a specific geographical area. The findings could also be useful for targeting changes to the built environment through land-use planning policies as a way to leverage higher public transport patronage. 
Planners may choose to more actively initiate modal conversion to achieve built environment effects, such as shifting from a frequent at grade bus service to light rail, or by adding a heavy rail station around which higher density development may be leveraged.

However, accounting for the large number of variables that can influence public transport ridership by mode, as identified by this study, can also poses practical challenges. Urban planning and development typically considers a subset of these variables only (e.g., population density, distance to public transport), with often limited information about socio-demographics. This issue therefore needs to be considered when applying the findings in practice.

There are also other limitations associated with this study. First, the analysis focused mainly on the origin end of commuting trips, as represented by household locations in small geographical areas across Melbourne (SA1s). While this allowed for a relatively large sample size to be used $(\mathrm{n}>10,000)$, future research should also consider attributes relevant to the destination end of commuting trips (e.g., car parking availability/price) as these have also been found to influence travel behavior (Cervero, 1994). Second, the analysis was limited to public transport commuting trips to work based on household locations in SA1s. Data was not available for other trip purposes and geographical areas at an equivalent (or greater) sample size, so this represents an opportunity for further research. Third, the analysis was cross-sectional in nature, thereby limiting the ability to attribute causation. Longitudinal studies are particularly rare in this context, typically hindered by a lack of historic data on public transport service characteristics. However, efforts should be directed towards addressing this gap in future research to provide a stronger understanding of temporal effects and causality.

Despite the above limitations, this research has provided an understanding of how factors affecting commuting can vary by public transport mode within the same metropolitan region. The findings have important implications for public transport planning and policy, not only in terms of improving demand forecasting but also in how efforts can be better directed towards increasing transit ridership by mode. Doing so can help to deliver a range of wider societal benefits through reduced car dependency and social exclusion, plus enhanced road safety, sustainability and health outcomes.

\section{Acknowledgements}

Sincere thanks go to Craig Somerville (Victorian Department of Transport) and James Eunson (AE$\mathrm{COM}$ ) for their assistance in providing the public transport related data used in this research. The authors are also very grateful for the insightful comments provided by three anonymous reviewers which helped to strengthen this paper. Any errors or omissions in this paper are the sole responsibility of the authors. 


\section{References}

ABS. (2016). Census of population and housing data. Retrieved from http://www.abs.gov.au/census

ABS. (2018). 3222.0-Population projections, Australia, 2017 (base)-2066. Retrieved from http:// www.abs.gov.au/census

ABS. (2019). 3218.0-Regional population growth, Australia, 2017-18. Retrieved from http://www. abs.gov.au/census

Akbari, S., Mahmoud, M. S., Shalaby, A., \& Nurul Habib, K. M. (2018). Empirical models of transit demand with walk access/egress for planning transit oriented developments around commuter rail stations in the Greater Toronto and Hamilton Area. Journal of Transport Geography, 68, 1-8.

Allison, P. D. (1999). Logistic regression using the SAS system: Theory and application. Cary, NC: SAS Publishing.

Arrington, G., \& Cervero, R. (2008). Effects of TOD on housing, parking and travel (TCRP Report 128). Retrieved from http://ctod.org/pdfs/2007TCRP128.pdf

Aston, L., Currie, G., \& Pavkova, K. (2016). Does transit mode influence the transit-orientation of urban development?-An empirical study. Journal of Transport Geography, 55, 83-91.

Australian Transport Council. (2006). National guidelines for transport system management in Australia, Volume 4: Urban transport. Retrieved from https://www.atap.gov.au/sites/default/files/National_ Guidelines_Volume_4.pdf

Badland, H., Rachele, J. N., Roberts, R., \& Giles-Corti, B. (2017). Creating and applying public transport indicators to test pathways of behaviors and health through an urban transport framework. Journal of Transport \& Health, 4, 208-215.

Bakhru, A., Watten, M., \& Kilim, G. R. (2017). DDOT MXD + Phase 4 update: Model development report-2017 update (DDOT-RDT-17-01).

Boulange, C., Gunn, L., Giles-Corti, B., Mavoa, S., Petit, C., \& Badland, H. (2017). Examining associations between urban design attributes and transport mode choice for walking, cycling, public transport and private motor vehicle trips. Journal of Transport \& Health, 6, 155-166.

Broadstock, D. C. (2009). An econometric study of the relationship between land use and vehicle trip generations (TRICS Research Report 09/1). Retrieved from http://www.trics.org/research_lib.aspx

Broadstock, D. C., Collins, A., \& Hunt, L. C. (2010). Modelling car trip generations for UK residential developments using data from TRICS. Transportation Planning and Technology, 33(8), 671-678.

Cervero, R. (1994). Transit-based housing in California: Evidence on ridership impacts. Transport Policy, 1(3), 174-183.

Cervero, R. (2007). Transit-oriented development's ridership bonus: A product of self-selection and public policies. Environment and Planning A, 39, 2068-2085.

Cervero, R., \& Arrington, G. B. (2008). Vehicle trip reduction impacts of transit-oriented housing. Journal of Public Transportation, 11(3), 1-17.

Cervero, R., Ferrell, C., \& Murphy, S. (2002). Transit-oriented development and joint development in the United States: A literature review. Transportation Research Digest, 52, 1-144.

Cervero, R., \& Kockelman, K. (1997). Travel demand and the 3Ds: Density, diversity, and design. Transportation Research Part D, 2(3), 199-219.

Cervero, R., \& Murakami, J. (2010). Effects of built environments on vehicle miles traveled: Evidence from 370 US urbanized areas. Environment and Planning A, 42, 400-418.

Cervero, R., Murphy, S., Ferrell, C., Tsai, Y.-H., Goguts, N., Amado, C., . . Witenstein, N. (2004). Transit-oriented development in the United States: Experiences, challenges, and prospects (TCRP Report 102). Retrieved from http://www.trb.org/Publications/Blurbs/154989.aspx 
Chow, L.-F., Zhao, F., Liu, Z., Li, M.-T., \& Ubaka, I. (2006). Transit ridership model based on geographically weighted regression. Transportation Research Record: Journal of the Transportation Research Board, 1972, 105-114.

Clifton, K. J., Currans, K. M., Cutter, A. C., \& Schneider, R. (2012). Household travel survey in context-based approach for adjusting ITE trip generation rates in urban contexts. Transportation Research Record: Journal of the Transportation Research Board, 2307, 108-119.

Clifton, K. J., Currans, K. M., \& Muhs, C. D. (2015). Adjusting ITE's trip generation handbook for urban context. Journal of Transport and Land Use, 8(1), 5-29.

Crane, R. (2000). The influence of urban form on travel: An interpretive review. Journal of Planning Literature, 15(1), 3-23.

Cullinane, S. (2002). The relationship between car ownership and public transport provision: A case study of Hong Kong. Transport Policy, 9(1), 29-39.

Currans, K. M., \& Clifton, K. J. (2015). Using household travel surveys to adjust ITE trip generation rates. Journal of Transport and Land Use, 8(1), 85-119.

Currie, G. (2010). Quantifying spatial gaps in public transport supply based on social needs. Journal of Transport Geography, 18(1), 31-41.

De Gruyter, C., Currie, G., \& Rose, G. (2016). Sustainability measures of public transport in Cities: A world review and focus on the Asia/Middle East region. Sustainability, 9(43), 1-21.

Department of Transport. (2019a). Principal public transport network. Retrieved from https://transport.vic.gov.au/about/planning/principal-public-transport-network

Department of Transport. (2019b). Victorian integrated survey of travel and activity. Retrieved from https://transport.vic.gov.au/about/data-and-research/vista

Dill, J., Schlossberg, M., Ma, L., \& Meyer, C. (2013). Predicting transit ridership at the stop level: The role of service and urban form. Paper presented at the 92nd Transportation Research Board (TRB) Annual Meeting, Washington, DC.

Evans, J. E., Pratt, R. H., Stryker, A., \& Kuzmyak, J. R. (2007). Traveler response to transportation system changes: Chapter 17-Transit oriented development (TCRP Report 95). Retrieved from https://www. nap.edu/read/14077/chapter/2

Ewing, R., \& Cervero, R. (2010). Travel and the built environment: A meta-analysis. Journal of the American Planning Association, 76(3), 265-294.

Ewing, R., DeAnna, M., \& Li, S.-C. (1996). Land-use impacts on trip generation rates. Transportation Research Record: Journal of the Transportation Research Board, 1518, 1-6.

Ewing, R., Greenwald, M., Zhang, M., Walters, J., Feldman, M., Cervero, R., ... Thomas, J. (2011). Traffic generated by mixed-use developments-Six-region study using consistent built environment measures. Journal of Urban Planning and Development, 137(3), 248-261.

Ewing, R., \& Hamidi, S. (2014). Longitudinal analysis of transit's land use multiplier in Portland (OR). Journal of the American Planning Association, 80(2), 123-137.

Ferrari, S., \& Cribari-Neto, F. (2004). Beta regression for modelling rates and proportions. Journal of Applied Statistics, 31(7), 799-815.

Gamas, J. A., Anderson, W. P., \& Pastor, C. (2006). Estimation of trip generation in Mexico City, Mexico, with spatial effects and urban densities. Transportation Research Record: Journal of the Transportation Research Board, 1985, 49-60.

Goodwin, P. (1993). Car ownership and public transport use: Revisiting the interaction. Transportation, 20(1), 21-33.

Gulden, J., Goates, J. P., \& Ewing, R. (2013). Mixed-use development trip generation model. Transportation Research Record: Journal of the Transportation Research Board, 2344, 98-106. 
Handy, S., Cao, X., \& Mokhtarian, P. (2005). Correlation or causality between the built environment and travel behavior? Evidence from Northern California. Transportation Research Part D, 10, 427444.

Hendricks, S., Winters, P., Wambalaba, F., Barbeau, S., Catala, M., Thomas, K., . . Goodwill, J. (2005). Impacts of transit-oriented development on public transportation ridership. Retrieved from https://scholarcommons.usf.edu/cgi/viewcontent.cgi?article=1238\&context=cutr_nctr

Kasraian, D., Maat, K., Stead, D., \& Van Wee, B. (2016). Long-term impacts of transport infrastructure networks on land-use change: An international review of empirical studies. Transport Reviews, 36(6), 772-792.

Kieschnick, R., \& McCullough, B. D. (2003). Regression analysis of variates observed on (0, 1): Percentages, proportions and fractions. Statistical Modelling, 3, 193-213.

Kim, J., Delbosc, A., \& De Gruyter, C. (2017). Estimating residential public transport trip generation rates. Paper presented at the Australian Institute of Traffic Planning and Management (AITPM) National Conference, Melbourne, Australia.

Lin, J.-J., \& Yu, T.-P. (2011). Built environment effects on leisure travel for children: Trip generation and travel mode. Transport Policy, 18(1), 246-258.

Loukaitou-Sideris, A., Higgins, H., Cuff, D., \& Oprea, D. (2013). Up in the air: Urban design for light rail transit stations in highway medians. Journal of Urban Design, 18(3), 313-339.

Martin, M., Hard, E., Bochner, B., \& Hooper, K. (2018). Embracing change-Estimating site trip generation for smart growth development. Paper presented at the 97th Transportation Research Board (TRB) Annual Meeting, Washington, DC.

McKibbin, M. (2011). The influence of the built environment on mode choice-Evidence from the journey to work in Sydney. Paper presented at the 34th Australasian Transport Research Forum (ATRF), Adelaide, South Australia, Australia.

NASEM. (2006). Guidebook for evaluating, selecting, and implementing suburban transit services. Retrieved from https://www.nap.edu/catalog/13955/guidebook-for-evaluating-selecting-and-implementing-suburban-transit-services

Nasri, A., \& Zhang, L. (2014). The analysis of transit-oriented development (TOD) in Washington, DC and Baltimore metropolitan areas. Transport Policy, 32, 172-179.

Nguyen-Phuoc, D. Q., Currie, G., De Gruyter, C., \& Young, W. (2018). Congestion relief and public transport: An enhanced method using disaggregate mode shift evidence. Case Studies on Transport Policy, 6(4), 518-528.

OECD. (2019). The OECD Metropolitan eXplorer. Retrieved from https://measuringurban.oecd.org

PTV. (2012). Early history of public transport. Retrieved from https://web.archive.org/ web/20120807063057/http://corp.ptv.vic.gov.au/managing-victoria-s-public-transport-network/history-and-heritage/early-history-of-public-transport/

PTV. (2019a). Ferries. Retrieved from https:/www.ptv.vic.gov.au/more/travelling-on-the-network/ferries/

PTV. (2019b). Metropolitan fares. Retrieved from https://www.ptv.vic.gov.au/tickets/fares/metropolitan-fares/

PTV. (2019c). Operator contact details. Retrieved from https://www.ptv.vic.gov.au/footer/customerservice/operator-contact-details/

PTV. (2019d). Public transport partnership agreements. Retrieved from https://www.ptv.vic.gov.au/ footer/legal-and-policies/public-transport-partnership-agreements/

PTV. (2019e). Timetables. Retrieved from https://www.ptv.vic.gov.au/timetables

Renne, J. (2009). From transit-adjacent to transit-oriented development. Local Environment, 14(1), 
$1-15$.

Renne, J., Hamidi, S., \& Ewing, R. (2016). Transit commuting, the network accessibility effect, and the built environment in station areas across the United States. Research in Transport Economics, 60, $35-43$.

Ryan, S., \& Frank, L. (2009). Pedestrian environments and transit ridership. Journal of Public Transportation, 12(1), 39-57.

Spiridonos, F. (2013). Transport demand modelling in Melbourne. Paper presented at the 19th International Conference on Urban Transport and the Environment, Kos, Greece.

State of Victoria. (2019). Delivering for all Victorians: Victorian budget 19/20 service delivery (Budget paper No. 3). Retrieved from https://www.dtf.vic.gov.au/2019-20-state-budget/2019-20-servicedelivery

Stevens, M. R. (2017). Does compact development make people drive less? Journal of the American Planning Association, 83(1), 7-18.

Stojanovski, T. (2020). Urban design and public transportation - Public spaces, visual proximity and transit-oriented development (TOD). Journal of Urban Design, 25(1), 134-154.

Taylor, B. D., Miller, D., Iseki, H., \& Fink, C. (2009). Nature and/or nurture? Analyzing the determinants of transit ridership across US urbanized areas. Transportation Research Part A, 43, 60-77.

Tian, G., Ewing, R., White, A., Hamidi, S., Walters, J., Goates, J. P., \& Joyce, A. (2015). Traffic generated by mixed-use developments: Thirteen-region study using consistent measures of built environment. Transportation Research Record: Journal of the Transportation Research Board, 2500, 116-124.

Tian, G., Park, K., \& Ewing, R. (2018). Trip and parking generation rates for different housing types: Effects of compact development. Paper presented at the 97th Transportation Research Board (TRB) Annual Meeting, Washington, DC.

Truong, L. T., \& Currie, G. (2019). Macroscopic road safety impacts of public transport: A case study of Melbourne, Australia. Accident Analysis \& Prevention, 132, Article no. 105270, pp. 1-10.

Tsai, C.-H., Mulley, C., \& Clifton, G. (2012). The spatial interactions between public transport demand and land-use characteristics in the Sydney Greater Metropolitan Area. Road \& Transport Research, 21(4), 62-73.

UITP. (2015). Mobility in cities database 2015. Retrieved from https:/www.uitp.org/publications/ mobility-in-cities-database/

Victorian Government. (2019). DataVic. Retrieved from https://data.vic.gov.au/

Westrom, R., Dock, S., Henson, J., Watten, M., Bakhru, A., Ridgway, M., . . Paradkar, R. (2017). Multimodal trip generation model to assess travel impacts of urban developments in the District of Columbia. Transportation Research Record: Journal of the Transportation Research Board, 2668, 29-37.

Zamir, K. R., Nasri, A., Baghaei, B., Mahapatra, S., \& Zhang, L. (2014). Effects of transit-oriented development on trip generation, distribution, and mode share in Washington, D.C., and Baltimore, Maryland. Transportation Research Record: Journal of the Transportation Research Board, 2413, 45-53.

Zegras, C. (2010). The built environment and motor vehicle ownership and use: Evidence from Santiago de Chile. Urban Studies, 47(8), 1793-1817.

Zhang, L., Hong, J., Nasri, A., \& Shen, Q. (2012). How built environment affects travel behavior: A comparative analysis of the connections between land use and vehicle miles traveled in US cities. Journal of Transport and Land Use, 5(3), 40-52. 